\title{
MANIPULAÇÃO MIDIÁTICA: ANÁLISE DAS IMAGENS PUBLICADAS NA ÚLTIMA EDIÇÃO DA REVISTA VEJA EM 2010
}

\section{ENSAIO TEÓRICO}

STUMPF, Katiusa ${ }^{1}$

STUMPF, Katiusa. Manipulação midiática: Análise das imagens publicadas na última edição da Revista Veja em 2010. Revista Científica Multidisciplinar Núcleo do Conhecimento. Ano 05, Ed. 06, Vol. 08, pp. 24-37. Junho de 2020. ISSN: 2448-0959, Link de

acesso: https://www.nucleodoconhecimento.com.br/comunicacao/manipulacaomidiatica

\section{RESUMO}

Neste artigo são abordados alguns aspectos sobre a manipulação de informações efetuada por parte da imprensa brasileira. Destaca-se a utilização dos padrões de manipulação explicitados por Perseu Abramo, sendo esses empregados na análise das imagens publicadas na revista Veja em 29 de dezembro de 2010, referentes a passagem do governo Lula para o governo Dilma, ambos do Partido dos Trabalhadores. É feita uma abordagem acerca da utilização das mídias como ferramentas para regulação da sociedade de acordo com interesses políticos e econômicos da imprensa. Também são discutidos os processos de comunicação por meio de codificação e decodificação de informações. Os resultados da análise comprovam a existência de manipulação midiática na edição analisada da revista Veja.

\footnotetext{
${ }^{1}$ Mestrado em Ciência da Informação pela UFSC; Especialização em Fotografia pela UEL; Graduação em Biblioteconomia pela UFSC.
} 
Palavras-chave: Manipulação Midiática, padrões de manipulação, Perseu Abramo, análise de imagem, Revista Veja.

\section{INTRODUÇÃO}

$\mathrm{Na}$ sociedade da informação ou sociedade do conhecimento decorrente do advento das novas tecnologias, pode-se dizer que as mídias representam ferramentas com significativo poder de influência na formação de opinião dos indivíduos que a compõem e regulam. Assim, a grande imprensa pode ser entendida, atualmente, como uma coluna de sustentação do poder que organiza uma sociedade. Para alguns ela seria o quarto poder, além dos três poderes: executivo, legislativo e judiciário. Isso se dá porque na atual conjuntura brasileira a imprensa é imprescindível como fonte legitimadora das medidas políticas anunciadas pelos governantes, das estratégias de mercado das grandes corporações e pelo capital financeiro.

Pode-se inferir, conforme as palavras de José Arbex Jr., que a imprensa "Constrói consensos, educa percepções, produz 'realidades' parciais apresentadas como a totalidade do mundo, mente, distorce os fatos, falsifica, mistifica [...]". (ABRAMO, 2003, p.8). Ou seja, a imprensa atua como um "partido" que defende os interesses específicos de seus proprietários privados, ignorando os interesses da população brasileira. Essa é a discussão que norteia esse artigo.

Com base em uma fundamentação teórica referenciada e disposta no final deste texto, argumenta-se sobre as mídias, principalmente acerca do poder de dominação dos meios de comunicação por meio de manipulação e instrumentos simbólicos. Para isso é realizada a análise das imagens publicadas na revista Veja em sua edição de 29 de dezembro de 2010, conforme os padrões de manipulação da grande imprensa brasileira, explicitados por Perseu Abramo, experiente jornalista que também atuou como professor de jornalismo por alguns anos. 


\section{MANIPULAÇÃO MIDIÁTICA NA SOCIEDADE DA INFORMAÇÃO}

Em um país como o Brasil, ainda em desenvolvimento, sabe-se que as poucas verbas governamentais não atingem a base da estrutura social, ou seja, a Educação. Isso faz com que a maior parte da população careça de preparo para lidar com tantos avanços tecnológicos e possibilidades de acesso a informação, bem como de capacidade para reflexão sobre tais informações. Neste contexto destaca-se a questão da exclusão ao acesso as novas tecnologias da informação e, portanto, a importância das mídias, principalmente a imprensa televisiva que representa o meio ou instrumento mediador da informação mais prático e popular no país, embora seja muito pouco utilizado para fins instrutivos, sendo geralmente adotado para manipulação em massa com finalidades comerciais e políticas.

Por isso, Mattelart e Mattelart (2003) questionam se a mídia é mediadora ou "antimediadora". Conforme os autores o que caracteriza os meios de comunicação de massa é o fato de esses serem "antimediadores", intransitivos e fabricantes da "nãocomunicação", ao considerar que a comunicação consiste na troca, na reciprocidade de uma fala. Desta forma o que predomina na relação entre mídias e indivíduos é o poder de dominação e regulação social.

O processo pelo qual ocorre esse poder de dominação, através da formação de opinião pública, compreende um tipo de pensamento complexo descrito pelo sociólogo francês Edgar Morin (2000). O desafio da complexidade, segundo o autor, consiste no fato de que toda informação tem apenas um sentido em relação a uma situação. Isso significa que o sentido da palavra ou da imagem muda conforme o contexto, assim, para se conhecer não se pode isolar uma palavra ou uma informação, sendo necessário ligá-la a um contexto. Só se pode conhecer as partes conhecendo o todo em que se situam.

Outro texto que contribui para essa discussão intitula-se "Designação: a arma secreta, porém incrivelmente poderosa, da mídia em conflitos internacionais", de Kanavillil Rajagopalan (2003), doutor em linguística aplicada e pós-doutor em filosofia da linguagem. É um texto que trata da influência midiática na concepção social, 
fundamentando-se com a ideia de que tudo pode e deve ser contestado, abordando também a questão dos termos de designação do discurso jornalístico na formação de opinião pública favorável ao mesmo; os eufemismos utilizados em função de minimizar a culpa dos responsáveis pelas tragédias ocorrentes no mundo e, ressaltando, ainda, o poder de designação de referência neutra, ao agregar valores através da nominação.

De acordo com Morin (2000) e Rajagopalan (2003), portanto, existe um pensamento complexo que inclui texto ou imagem e contexto e que está sempre presente nas informações transmitidas por meio das mídias. Desta forma os donos dos meios de comunicação são detentores de poder sobre a formação de opinião pública, de regulação da sociedade.

Em entrevista Stuart Hall define isso como um processo de codificação e de decodificação dos termos de linguagem, tratando do "ler entre linhas" como uma questão mais complexa do que a princípio pode parecer. Conforme o autor:

[...] "Codificação/Decodificação" [...] A mensagem é uma estrutura complexa de significado que não é tão simples como se pensa. A recepção não é algo aberto e perfeitamente transparente, que acontece na outra ponta da cadeia de comunicação. E a cadeia comunicativa não opera de forma unilinear. [ ] No contexto político existe, ainda, a noção [...] de que o significado não é fixo, de que não existe uma lógica determinante global que nos permita decifrar o significado ou o sentido ideológico da mensagem contra alguma grade. A noção de que o sentido sempre possui várias camadas, de que ele é sempre multirreferêncial (SOVIK, 2003, p. 354).

Os donos dos meios de comunicação utilizam-se das mídias como ferramentas para manipulação em massa. Para isso é adotado este processo de "pensamento complexo", no qual se dá a codificação e decodificação. Ou seja, cada mensagem codificada aparentemente pressupõe determinada decodificação, desta forma as informações transmitidas pelas mídias são codificadas exatamente da maneira que se 
deseja que elas sejam decodificadas ou interpretadas, de modo a influenciar, como bem entender, a opinião pública. Assim, somente os mais perspicazes ou bem instruídos conseguem ir além da aparente decodificação, adentrando o contexto político e a noção de que os significados não são fixos e de que nem tudo é o que parece ser. Por meio das mídias é possível estabelecer um forte poder de designação, de influência, até mesmo cultural, que muitas vezes acaba construindo a realidade social dos indivíduos.

Mattelart e Mattelart (2003) reportam-se para as teses de Foucault e trazem para essa discussão o modelo utópico de organização social em "Panóptico" que consiste em uma torre central de onde se pode controlar com plena visibilidade todo o círculo de um prédio dividido em alvéolos onde os vigiados encontram-se confinados em células individuais, separados uns dos outros, sendo vistos sem se ver. Trata-se de uma caracterização do modo de controle exercido pelo dispositivo televisual para organizar o espaço, controlar o tempo, vigiar o indivíduo e regular seus comportamentos. Neste caso as mídias televisivas representam o "Panóptico Invertido" no qual os vigiados podem ver sem ser vistos.

Para Morin (2000) "somos produtos produtores" o que significa que os indivíduos são produtores da sociedade porque sem indivíduos não existe sociedade, desta forma, a existência de uma sociedade com sua cultura, normas, leis, regras, etc. produz esses indivíduos. Ou seja, os indivíduos produzem a sociedade e a sociedade produz os indivíduos como um processo que se dá em um ciclo vicioso. Nisso consiste o pensamento complexo e o poder das mídias na regulação da sociedade por meio da disseminação de determinadas ideias, na produção de indivíduos produtores da sociedade ideal para os donos das mídias, para o sistema capitalista que estabelece uma sociedade de consumo, inclusive do consumo da informação e do conhecimento.

Isso significa ainda que damos vida às nossas ideias e, uma vez que Ihes damos vida, são elas que indicam o nosso comportamento, que nos mandam matar ou morrer por elas; vale dizer que tais produtos são os nossos próprios produtores [...] (MORIN, 2000, p. 25.) 
Neste contexto e utilizando-se de termos como "comercialização do conhecimento" e "indústria cultural" Burke (2003) destaca que uma das razões para se afirmar que a sociedade atual pode ser definida como sociedade da informação é que a produção e a venda de informações contribui de maneira considerável para as economias mais desenvolvidas.

Segundo Morin (2000) o objetivo do pensamento complexo é contextualizar e globalizar. O que, na discussão da temática apresentada nesse artigo, consiste no entendimento de quem é o indivíduo e do que é a sociedade, de qual a relação entre ambos e o que as mídias representam nessa relação. Uma vez compreendidas essas questões, os indivíduos podem ter autonomia e sabedoria na regulação da sociedade que constituem, de forma a se libertar um pouco das amarras de um sistema maior, que é o capitalismo com seu jogo de poderes políticos. Assim, entende-se que a sociedade da informação e do conhecimento representa uma época na qual é possível se informar para conhecer os indivíduos e o contexto no qual encontram-se inseridos, bem como alcançar o entendimento de como isso tudo ocorre, possibilitando reflexões que não se deixam manipular por meio de instrumentos midiáticos.

Nesse sentido Abramo (2003) destaca os padrões de manipulação adotados pela grande mídia brasileira, demonstrando como é possível refletir e não se deixar enganar por tudo o que se lê e/ou se vê publicado por aí, conforme a abordagem do próximo tópico.

\section{PADRÕES DE MANIPULAÇÃO ADOTADOS PELA GRANDE IMPRENSA BRASILEIRA}

Em 1994 verificou-se, mais do que nunca, a necessidade em se discutir a questão da manipulação midiática e a ética do jornalismo, quando ocorreu o conhecido, ou nem tão conhecido assim, caso da "síndrome da antena parabólica", conforme divulgado por Kucinski (1998). Tratava-se do incidente ocorrido nos bastidores do Jornal Nacional, da TV Globo, no decorrer da primeira disputa presidencial entre Luiz Inácio Lula da Silva e Fernando Henrique Cardoso, quando Rubens Ricupero, o então 
ministro da Fazenda, confidenciou ao jornalista Carlos Monforte sua falta de escrúpulos na campanha política, favorecendo Fernando Henrique.

Ocorre que esta conversa que deveria ser informal acabou sendo transmitida via satélite para antenas parabólicas em várias regiões do Brasil, fazendo com que os telespectadores tomassem conhecimento das falcatruas de políticos corruptos vinculados à imprensa manipuladora.

Esse flagra, no entanto, não foi suficiente para que a falta de ética no jornalismo brasileiro tivesse um fim. Com a falta de regulação da imprensa, os donos dos meios de comunicação estão livres para atuar como bem entendem, inclusive utilizando-se de padrões de manipulação.

Neste sentido Ayoub (2006) mostra como a revolução industrial contribui para que os europeus se desvencilhassem de quase um século de censura e restrições à imprensa, enquanto no Brasil essa regulação ainda não existe. Segundo Ayoub (2006) a imprensa brasileira cumpre um papel enquanto representação de classe, ela defende seus interesses burgueses e ataca os que a contestam. Os proprietários dos meios de comunicação querem e exigem participação no poder, interferindo não apenas no embate ideológico, como também na disputa política e no processo eleitoral.

Assim, acontecimentos como o da "síndrome da antena parabólica", dentre muitos outros, refletem o porquê de a necessidade da sociedade brasileira aprender a ler e a decodificar as informações, tanto de texto como de imagens. Essa é a mensagem principal passada pelo experiente jornalista e professor Perseu Abramo, ao tratar a questão dos padrões de manipulação adotados pela grande imprensa brasileira.

Por isso, destaca-se a utilidade de estudos que esclarecem como funciona a grande imprensa brasileira e como as informações podem ser decodificadas tendo seu real sentido identificado.

Ciente de tais questões, em seus estudos Abramo (2003) desmascara a dita objetividade da grande imprensa brasileira, mostrando que se trata de uma falsa 
objetividade. $\mathrm{O}$ autor situa o jornalismo praticado como um instrumento de controle político das elites, contrário aos interesses maiores do povo brasileiro. Para o jornalista, a verdadeira motivação da empresa de comunicação em manipular a informação e distorcer a realidade está principalmente no campo político, na lógica do poder e, em um segundo plano, no campo econômico, na busca do lucro. Mas é bastante frequente, sempre distorcendo de alguma forma a realidade, como esclarece o autor:

A maior parte do material que a imprensa oferece ao público tem algum tipo de relação com a realidade. Mas essa relação é indireta. É uma referência indireta à realidade, mas que distorce a realidade. Tudo se passa como se a imprensa se referisse à realidade apenas para apresentar outra realidade, irreal, que é a contrafação da realidade real. É uma realidade artificial, não-real, irreal [...]. (ABRAMO, 2003, p.23).

As técnicas de manipulação utilizadas pela grande imprensa brasileira, de acordo com Abramo (2003), ocorrem às vezes de maneira sutil, contida, outras vezes, de modo escancarado, grosseiro e até mesmo agressivo, pois ainda não existe uma regulação dos meios de comunicação no Brasil. A manipulação da informação se converte, assim, em manipulação da realidade.

A manipulação da imprensa ocorre de diversas formas, mas vale salientar que não é toda matéria que é manipulada, pois algumas delas precisam ser isentas para que a imprensa não seja totalmente desacreditada.

As técnicas de manipulação adotadas pela grande imprensa brasileira, conforme Abramo (2003) são as seguintes:

1. Padrão da Ocultação: Se refere à ausência e à presença dos fatos reais. Ocorre que muitas vezes acontece um deliberado silêncio sobre determinados fatos da realidade que são totalmente ignorados fazendo com que os leitores também os ignorem. Desta forma o fato real é eliminado da realidade e deixa de existir. 
2. Padrão da Fragmentação: Neste caso a realidade é fragmentada em vários outros minúsculos fatos particularizados, muitas vezes irrelevantes, se comparados com os fatos reais, com o todo. O fato real é fragmentado de forma que parte dele é isolada e apresentada fora do contexto original, de forma descontextualizada. Isso acaba gerando outros significados que não condizem com a realidade. Também pode ocorrer a invenção artificial e ficcional de outros fatos.

3. Padrão da Inversão: Neste caso, depois do fato ser fragmentado e descontextualizado, ainda tem suas partes reordenadas e, portanto, invertidas. O que gera uma bagunça completa que já não representa mais qualquer aspecto da realidade. Trata-se de uma destruição da realidade original e criação de uma nova realidade que é absolutamente artificial.

Existem várias formas de inversão: Inversão da relevância dos aspectos, quando o secundário é apresentado como o principal e vice-versa; Inversão da forma pelo conteúdo que ocorre quando o texto ou a imagem passa a ser mais importante do que o fato que está reproduzindo; Inversão da versão pelo fato, quando não é o fato real que toma importância, mas a versão dos fatos apresentada pelo órgão de imprensa; Inversão da opinião pela informação, quando a informação real é totalmente substituída pela opinião do órgão de imprensa, neste caso o juízo de valor é utilizado como se fosse um juízo de realidade. Nestes casos, conforme destaca o autor, é importante frisar que:

Essa particular inversão da opinião sobre a informação pode às vezes assumir caráter tão abusivo e absoluto que passa a substituir a realidade real até aos olhos do próprio órgão de informação. Não é incomum perceber que às vezes os responsáveis pelos órgãos cometem erros - aí, sim, involuntários - porque passaram a acreditar integralmente nas matérias do próprio órgão, sem perceber que elas não correspondem à realidade. (ABRAMO, 2003, p. 32).

4. Padrão de Indução: Refere-se ao fato de que, submetido, ora mais ou ora menos, aos padrões de manipulação da imprensa, o leitor é induzido a ver o mundo da mesma forma que o órgão de imprensa o vê. Ou seja, o leitor é 
induzido a ver o mundo não como ele realmente é, mas sim como querem que ele o veja.

5. Padrão Global: Este padrão é considerado específico do jornalismo de televisão e de rádio. Divide-se em três momentos básicos: exposição do fato, apresentação da fala de cidadãos que compõem a sociedade, apresentação da opinião de um especialista ou uma autoridade no assunto. Tudo isso junto favorece a manipulação fazendo com que o telespectador ou o ouvinte seja induzido a acreditar em informações inventadas pelos donos das mídias.

Assim, é possível compreender como ocorre o processo de manipulação midiática e utilizar esses ensinamentos deixados por Perseu Abramo aplicando-os em pesquisas e estudos que objetivem a análise de textos, sons e imagens mediados pela grande imprensa brasileira, tal qual se apresenta no próximo tópico.

\section{ANÁLISE DAS IMAGENS PUBLICADAS NA REVISTA VEJA NA EDIÇÃO DE 29 DE DEZEMBRO DE 2010}

Esse artigo baseia-se na análise das imagens publicadas pela revista Veja na edição de 29 de dezembro de 2010, especialmente a capa, que tem como objetivo anunciar a mudança de presidente que o Brasil viveria em 2011. Ao se deparar com a capa, o leitor logo pode perceber como é visível não se tratar de uma fotografia, e sim de imagem criada, uma ilustração. A construção da ideia e da imagem, que se utiliza das artes gráficas, foi bastante propícia e bem montada associando ao momento de transição do ano e do governo, como é possível observar: 
Figura 1 - Capa da revista Veja na edição de 29 de dezembro de 2010.

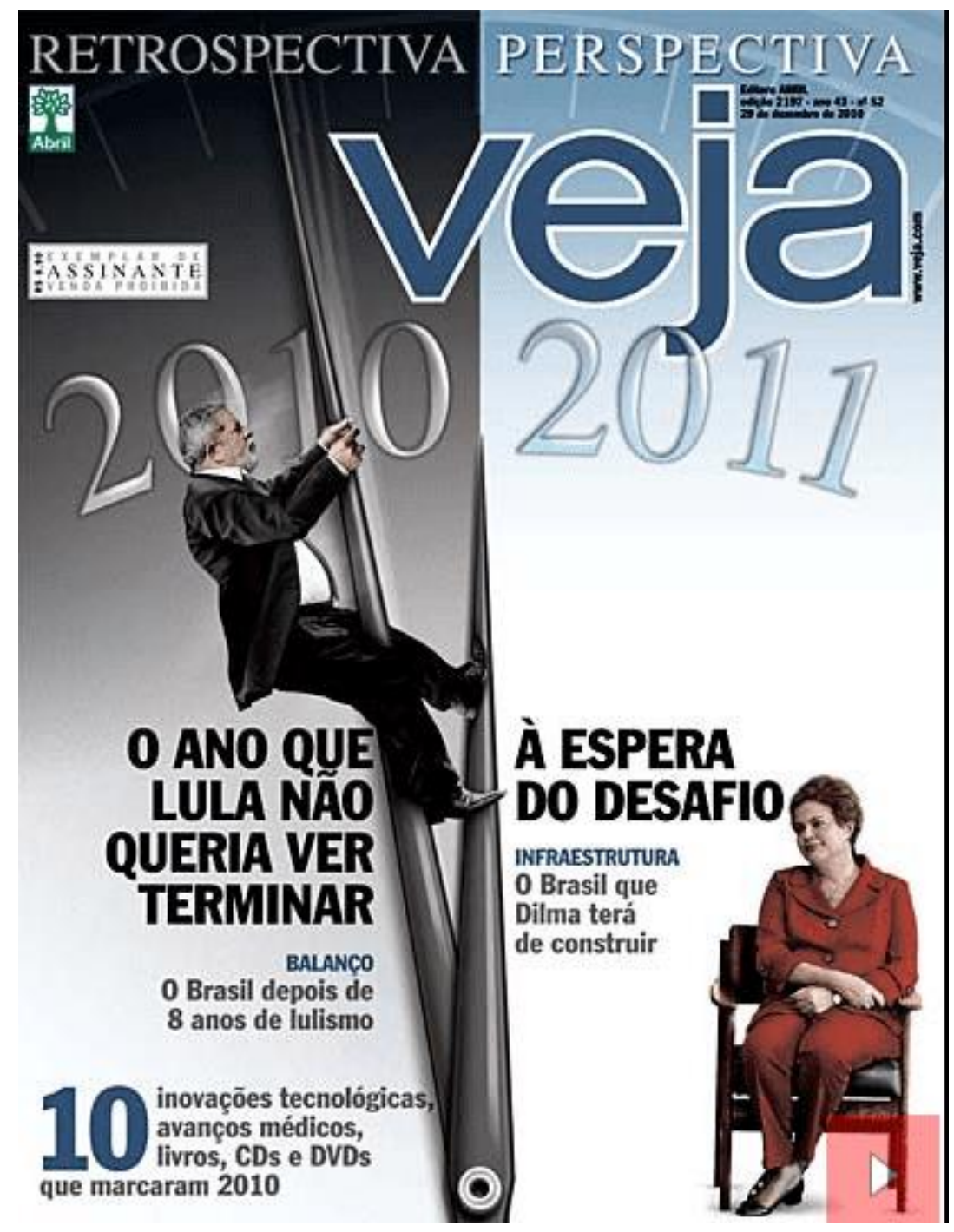

Fonte: Acervo digital da revista Veja

De um lado da capa, o então na data publicada, presidente Luiz Inácio Lula da Silva, é retratado em uma postura de resistência tentando impedir o avanço do ponteiro do relógio, que é constituído por uma arte sombreada favorecendo a ideia de movimento e de passagem de tempo, o final de seu mandato, ali representado pela virada do ano. Nessa análise é possível identificar que não se trata de uma fotografia, levando em consideração a posição do presidente integrado a ilustração do relógio.

Essa representação localiza-se do lado esquerdo da capa que possui o fundo preenchido com cores neutras que variam entre preto e cinza claro, o presidente está 
vestindo um terno preto, ajudando a reforçar a ideia de passado e memória. A palavra "Retrospectiva" também é anunciada na cor cinza e pouco destacada, completando essa linha de pensamento. As cores escuras e neutras ganham mais sentido de passado e remetem a algo que está prestes a virar memória, quando em comparação e contraste do outro lado da capa, onde se encontra, a então futura presidenta do Brasil, Dilma Roussef.

É possível observar um elaborado jogo de divisão e comparação entre o que teria se passado e o que estaria por vir, apresentado resumidamente com as palavras: "Retrospectiva" e "Perspectiva", na parte superior da capa. No centro, acompanhando a ilustração, se encontram os textos objetivos que se opõem em meio ao processo de comparação: "O ano que Lula não queria ver terminar", "Balanço - O Brasil depois de 8 anos de lulismo", de um lado, acompanhando a imagem de Lula, enquanto do outro lado, juntamente com a imagem de Dilma, aparecem as seguintes frases: "À espera do desafio" e "Infraestrutura - O Brasil que Dilma terá de construir". Um contraste com texto e imagem se completando de forma harmônica.

Do lado direito da capa, preenchida com fundo azul e branco representando o ano de 2011, ano de posse do novo presidente ou presidenta do país, está Dilma Roussef sentada, com mãos cruzadas repousadas sobre as pernas como se estivesse aguardando o desafio deixado por Lula. A figura da presidenta vestida de vermelho remete ao Partido dos Trabalhadores e seu rosto não demonstra alegria nem tristeza, mas talvez uma certa preocupação, ansiedade ou medo escondidos em um sorriso contido.

O uso da palavra "desafio" cabe como uma crítica e provocação da revista ao governo anterior, mesmo que ambos os governos sejam pertencentes ao mesmo partido, Veja deixa claro a sua própria insatisfação quanto ao que foi desenvolvido no governo de Lula.

A capa contém elementos explícitos sobre a opinião da revista para determinado momento. Uma vez que a capa mostra o Lula agarrado ao poder sem querer sair de lá e deixando "problemas", ou seja, a necessidade de se construir um novo país. A 
revista Veja faz questão de explicitar seu desgosto com o governo Lula, como também é possível observar na matéria que leva o título de "Uma constelação sem brilho" onde a opinião sobre as escolhas de Dilma é citada e que estas prometeriam "muita confusão".

A sessão que trata da infraestrutura - "a missão de construir", aborda diversos problemas que o país enfrenta e enfrentará, a revista conseguiu incluí-los na palavra direcionada e vinculada à Dilma na capa da revista; "Perspectiva". Palavra que parece ter sido carregada de cobranças e esperança da população brasileira, mas que na realidade reflete mesmo a opinião da revista Veja, uma vez que a grande maioria da população aprovou o governo Lula.

A matéria que faz uma retrospectiva dos oito anos de mandato do presidente Lula, leva o título de "fecham-se as cortinas, termina o espetáculo" acompanhada por uma fotografia quase panorâmica do presidente descalço em um campo, de braços abertos e que apesar de estar de perfil, apresenta uma feição tranquila e de alívio, ironicamente texto e imagem parecem ter sido montados para insinuar que o mandato de Lula foi um teatro, um espetáculo.

A matéria conta, ainda, com outras fotografias de suas viagens, também em preto e branco, mais uma vez submetendo a ideia de memória, passado e de caráter documental.

A parte da retrospectiva, criada pela revista Veja, trata dos dias de revolta da população e protestos contra o governo Lula, encontram-se repletos de textos críticos e de ataque ao governo realizado nesses oito anos, como se o governo tivesse sido duramente criticado pela população durante seu governo e não tivesse recebido apoio, embora tenha sido o governo avaliado com o maior índice de satisfação da população brasileira em toda sua história.

Ao citar a melhoria de vida de uma parcela dos brasileiros que tiveram mudança em seu padrão de vida nesse tempo, Veja apresenta retratos de pessoas satisfeitas com o governo e com postura de orgulho de serem o que são. Mesmo citando e 
reconhecendo mudanças positivas ocorridas, a revista nomeia essa sessão de "miséria".

De acordo com Abramo (2003), o padrão de indução aplicado juntamente a formação da notícia, faz com que o leitor veja o mundo da forma que o órgão de comunicação vê e induz a acreditar que essa é a realidade de fato. Essa indução começa no surgimento da ideia e na formação da imagem irreal, pois não se trata de uma fotografia que relata a realidade, passa pelos pequenos textos utilizados na capa, pelo destaque da manchete e se estende ao texto da matéria final.

Não houve preocupação em ilustrar a capa com uma imagem real, que apresentasse a realidade tal como ela é. Em vez disso é exposta uma imagem criada pela Veja, ou seja, uma artimanha de manipulação que cria uma falsa realidade, mostrando uma atmosfera de desamparo e de dúvida na capacidade da futura presidenta. Fica no ar a dúvida criada pela Veja: "Como será que Dilma irá encarar esse desafio?", E os falsos problemas - também criados pela Veja - deixados pelo governo anterior: "Será que ela será capaz de resolver todos os problemas que Lula deixou?". A revista deixa explicita a ideia de que não acredita, não confia ou não apoia o futuro governo. Isso acontece também, de forma explícita, quando Dilma anuncia, segundo a revista, uma péssima escolha do ministério, induzindo o leitor a acreditar e concordar com sua posição.

A informação não chega ao leitor de forma objetiva e clara, para que ele possa fazer sua leitura, refletir e tirar suas próprias conclusões. A revista Veja incorpora sua opinião nas matérias jornalísticas que publica e faz com que uma falsa realidade seja divulgada como uma verdade absoluta.

\section{CONSIDERAÇÕES FINAIS}

Os resultados comprovam a existência de manipulação midiática na edição analisada da revista Veja. Por fim, percebe-se que a imagem publicitada pela grande imprensa brasileira pode ser passível de inúmeros significados, por isso, para ter seu conteúdo decodificado, requer leitura e análise de suas intenções representativas. $O$ que pode 
ocorrer por meio de um pensamento reflexivo que seja estimulado numa sociedade educativa, a fim de formar cidadãos capazes de um entendimento amplo e globalizado que não se deixa manipular.

\section{REFERÊNCIAS}

ABRAMO, Perseu. Padrões de manipulação na grande imprensa. São Paulo: Editora Fundação Perseu Abramo, 2003.

AYOUB, Ayoub Hanna. Mídia e movimentos sociais: a satanização do MST na Folha de São Paulo. 2006. 169 p. Dissertação (Mestrado em Ciências Sociais) Universidade Estadual de Londrina, Londrina, PR.

BURKE, Peter. Uma história social do conhecimento: de Gutenberg a Diderot. Rio de Janeiro: Zahar Ed., 2003.

KUCINSK, Bernardo. A síndrome da antena parabólica: ética no jornalismo brasileiro. São Paulo, Editora Fundação Perseu Abramo, 1998.

MATTELART, Armand; MATTELART, Michéle. História das teorias da comunicação. 6. ed. São Paulo: Loyola, 2003.

MORIN, Edgar. Da necessidade de um pensamento complexo. In: MARTINS, Francisco Menezes; SILVA, Juremir Machado da (Org.). Para navegar no século XXI: tecnologias do imaginário e cibercultura. 2. ed. Porto Alegre: EDIPUCRS, 2000. p.1942.

RAJAGOPALAN, Kanavillii. Designação: a arma secreta, porém incrivelmente poderosa, da mídia em conflitos internacionais. In: Por uma lingüística crítica: linguagem, identidade e a questão ética. São Paulo: Parábola Editorial. 2003.

SOVIK, Levi. (Org.). Reflexões sobre o modelo de codificação/decodificação: uma entrevista com Stuart Hall. In: HALL, Stuart. Da diáspora: identidades e mediações 
culturais. Belo Horizonte: Editora UFMG; Brasília: Representação da UNESCO no Brasil, 2003.

VEJA

(acervo

digital).

Disponível

em:

<http://veja.abril.com.br/acervodigital/home.aspx>. Acesso em: 15 de Maio 2010.

Enviado: Fevereiro, 2020.

Aprovado: Junho, 2020. 